\title{
Complete Remission of Colon Cancer with Ipilimumab Monotherapy
}

\author{
Sho Suzuki ${ }^{1,2}$, Hiroshi Kawakami ${ }^{1,3}$, Tadashi Miike ${ }^{1,2}$ and Shojiro Yamamoto ${ }^{1,2}$
}

Key words: ipilimumab, colon cancer, complete remission

(Intern Med 60: 957-958, 2021)

(DOI: 10.2169/internalmedicine.6024-20)

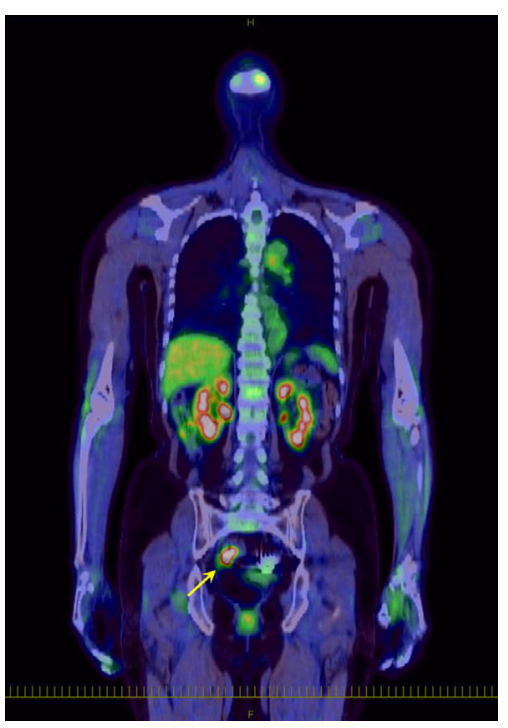

Picture 1.

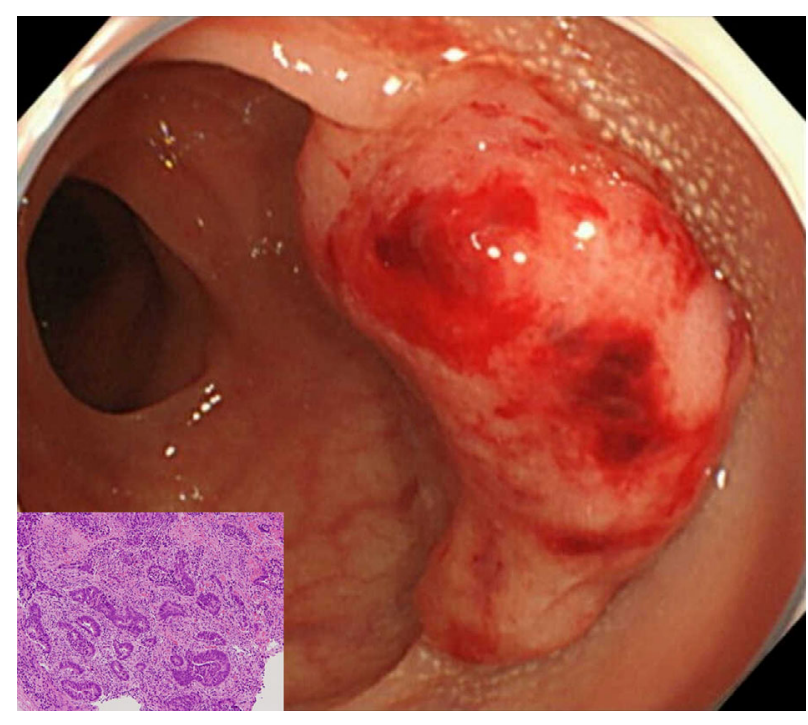

Picture 2.
A 71-year-old woman underwent surgery for stage IIA (T3aN0M0) melanoma of the right cheek in 2011. She had no family history of colorectal carcinoma. The melanoma recurred in April 2017 with metastasis to the cranial bones and right lung. She started nivolumab therapy $(3 \mathrm{mg} / \mathrm{kg}$ every 2 weeks). However, disease progression was evident in August 2018, and fluorodeoxy glucose (FDG)-positronemission tomography indicated a mass in the sigmoid colon (Picture 1). Colonoscopy revealed an advanced sigmoid colon carcinoma approximately $30 \mathrm{~mm}$ in diameter, and tubular adenocarcinoma was confirmed by a biopsy (Picture 2). The treatment was switched from nivolumab to ipilimumab (3 $\mathrm{mg} / \mathrm{kg}$ every 3 weeks). During the ipilimumab therapy, treatment was unchanged or not added for melanoma and colon carcinoma. After four cycles of ipilimumab treatment, the colonic tumor had scarred and disappeared completely; there were no residual tumor cells in the biopsy specimen (Picture 3). The U.S. Food and Drug Administration approved ipilimumab therapy for colorectal cancer (CRC) (1); however, there have been no reports of ipilimumab monotherapy for CRC. The effectiveness of ipilimumab monotherapy for CRC is unclear.

Informed consent was obtained from the patient for the publication of her information and imaging.

The authors state that they have no Conflict of Interest (COI).

\section{Acknowledgement}

The authors would like to thank Dr. Yuichiro Sato (Division of

\footnotetext{
${ }^{1}$ Department of Gastroenterology and Hepatology, Center for Digestive Disease and Division of Endoscopy, University of Miyazaki Hospital, Japan, ${ }^{2}$ Division of Gastroenterology and Hematology, Department of Internal Medicine, Faculty of Medicine, University of Miyazaki, Japan and ${ }^{3}$ Division of Gastroenterology and Hepatology, Department of Internal Medicine, Faculty of Medicine, University of Miyazaki, Japan Received: August 4, 2020; Accepted: September 8, 2020; Advance Publication by J-STAGE: October 21, 2020 Correspondence to Dr. Hiroshi Kawakami, hiropon@med.miyazaki-u.ac.jp
} 


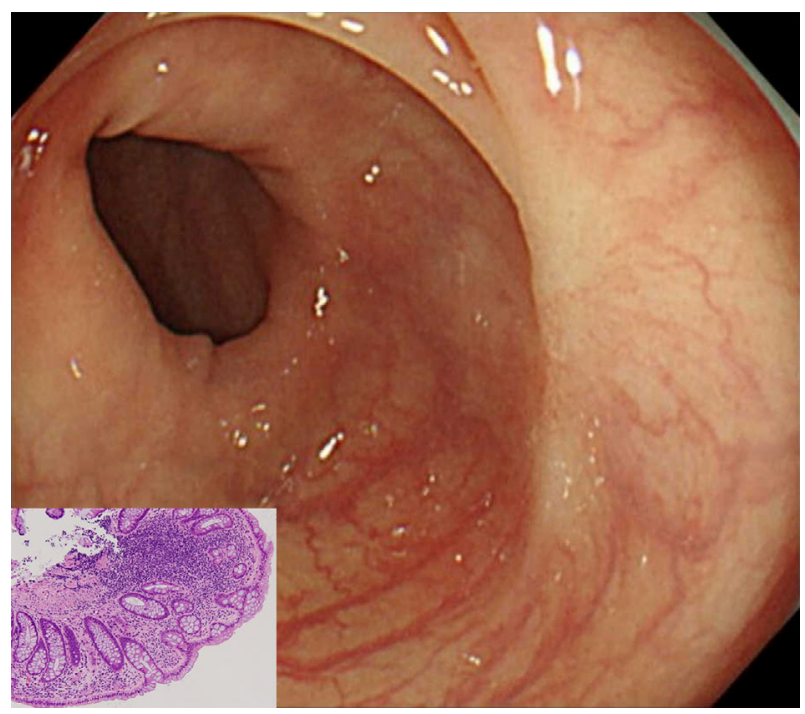

Pathophysiology, Department of Pathology Faculty of Medicine, University of Miyazaki, Japan) for the skillful analysis of the case pathology.

\section{Reference}

1. U.S Food and Drug Administration. FDA grants accelerated approval to ipilimumab for MSI-H or dMMR metastatic colorectal cancer [Internet]. [cited 2019 Oct 14]. Available from: https://ww w.fda.gov/drugs/resources-information-approved-drugs/fda-grants-a ccelerated-approval-ipilimumab-msi-h-or-dmmr-metastatic-colorect al-cancer

The Internal Medicine is an Open Access journal distributed under the Creative Commons Attribution-NonCommercial-NoDerivatives 4.0 International License. To view the details of this license, please visit (https://creativecommons.org/licenses/ by-nc-nd/4.0/).

Picture 3.

(C) 2021 The Japanese Society of Internal Medicine Intern Med 60: 957-958, 2021 